\title{
IN HALTSUUBERSICHT
}

$\S$ r. Staatsgebiet . . . . . . . . . . . . . . . . . 6

$\S$ 2. Unterbezirke . . . . . . . . . . . . . . . . . . . 7

$\S$ 3. Mittelbezirke . . . . . . . . . . . . . . . . 9

$\S$ 4. Sonderformen . . . . . . . . . . . . . . . . . . . . II

$\S$ 5. Politische Gemeinden. . . . . . . . . . . . . . . . . . I2

$\S 6$. Grenzen. . . . . . . . . . . . . . . . . . I6

\section{II}

\section{LEUTE}

$\S 7$. Freie . . . . . . . . . . . . . . . . I9

$\S$ 8. Geburtsadel. . . . . . . . . . . . . . . . . . 22

$\S$ 9. Optimaten . . . . . . . . . . . . . . . . . . 23

$\S$ Io. Ritter . . . . . . . . . . . . . . . . . . . . . . 26

$\S$ II. Klerus . . . . . . . . . . . . . . . . . . . . . 28

$\S$ I2. Freienklassen . . . . . . . . . . . . . . . . 28

§ 13. Freigelassene . . . . . . . . . . . . . . . . . . 3I

$\S$ I4. Minderfreie . . . . . . . . . . . . . . . . . 33

§ I5. Unfreie . . . . . . . . . . . . . . . . . . . . 35

§ 16. Ebenburt . . . . . . . . . . . . . . . . . . 39

$\S$ I7. Rechtsminderung . . . . . . . . . . . . . . . 40

$\S$ I8. Landfremde . . . . . . . . . . . . . . . . . . 40

III

HERRSCHER

§ I9. Kleinkönigtum. . . . . . . . . . . . . . . . . . . . . 44

$\S$ 20. Aufstieg des Königtums . . . . . . . . . . . . . . . . 48

$\S 2$ I. Niedergang des Königtums . . . . . . . . . . . . . . . 50

$\S 22$. Kaisertum . . . . . . . . . . . . . . . . . 52

§23. Immunität . . . . . . . . . . . . . . . . . 53

$\S 24$. Munt . . . . . . . . . . . . . . . . . . . . 56

$\S 25$. Grundherrschaft . . . . . . . . . . . . . . . 57 
§ 26. Blutsverwandtschaft . . . . . . . . . . . . . . . . . 64

§27. Sippe. . . . . . . . . . . . . . . . 66

$\S 28$. Verfall der Sippe. . . . . . . . . . . . 7 I

\$ 29. Ehe . . . . . . . . . . . . . . . . 73

§ 30. Ehegüterrecht. . . . . . . . . . . . . . 76

§ 3r. Eltern und Kinder . . . . . . . . . . . . . . . . . . 78

§32. Bundbrüderschaft ... . . . . . . . . . . . 80

§33. Ankindung und Gefolgschaft. . . . . . . . . . . 83

§34. Pflegeverwandtschaft. . . . . . . . . . . 85

$\mathrm{V}$

VERM ÖGEN

§35. Gesamteigentum an Liegenschaften. . . . . . . . . . . . 88

$\S 36$. Individualeigentum an Liegenschaften . . . . . . . . $9^{2}$

§37. Fahrhabe und Geld. . . . . . . . . . . . . . . . . 95

§38. Mobiliareigentum . . . . . . . . . . . . . . . 99

\$39. Nutzungsrechte . . . . . . . . . . . . . . ror

$\S 40$. Besitz . . . . . . . . . . . . . . . . . 105

$\S 4$ I. Schuld . . . . . . . . . . . . . . . I I07

$\S 42$. Haftung . . . . . . . . . . . . . . . . . . IIO

§ 43. Rechtsgeschäfte . . . . . . . . . . . . II5

$\S 44$. Geschäftsformen . . . . . . . . . . . . . . . II7

$\S 45$. Beurkundung . . . . . . . . . . . . . I22

VI

VERBRECHEN UND STRAFEN

$\S 46$. Friedensbruch . . . . . . . . . . . . I26

§ 47. Absichtslose Tat . . . . . . . . . . . . . . . . I28

$\S 48$. Haustiere und Unfreie . . . . . . . . . . . . . . I29

\$ 49. Neidingswerk . . . . . . . . . . . . . . . I30

§50. Geschütztes Gut, Tätermehrheit, Tateinheit . . . . . . . . I3I

§5I. Friedlosigkeit . . . . . . . . . . . . . I34

§52. Germanische Sakralstrafen . . . . . . . . . . . . . I37

§53. Mittelalterliche Strafen . . . . . . . . . . . . . . . I39

$\S 54$. Sühne . . . . . . . . . . . . . . . . . . I40

\$5. Verfolgungsrecht. . . . . . . . . . . I I44

§56. Privatstrafrecht . . . . . . . . . . . I45 
GERICHT UND RECHTSGANG seite

§57. Volksgericht. . . . . . . . . . . . . I48

§58. Schöffengericht . . . . . . . . . . . . . . I54

§59. Königsgericht . . . . . . . . . . . . . . . I57

$\S 60$. Privatgerichte . . . . . . . . . . . . . . 159

$\S 6 \mathrm{r}$. Älterer Rechtsgang . . . . . . . . . . . . . . . I6r

§62. Jüngerer Rechtsgang. . . . . . . . . . . . . . I65

§63. Älteres Beweisverfahren. . . . . . . . . . . . . . I66

$\S 64$. Zweikampf . . . . . . . . . . . . I72

$\S 65$. Jüngeres Beweisverfahren. . . . . . . . . . . . I74

$\S 66$. Vollstreckung . . . . . . . . . . . . . I77

\section{REGISTER}
A. Autoren . . . . . . . . . . . . I83
B. Personennamen . . . . . . . . . . . . . I84
C. Ortsnamen . . . . . . . . . . . . I85
D. Quellen. . . . . . . . . . . . . I85
E. Sachregister . . . . . . . . . . . . I86
F. Terminologie ...............2II 